\title{
GIS Based Services Using Network Analysis of Khartoum North
}

\author{
Mohamed Elamin Ahmed Babiker \\ Department of Surveying Engineering, College of \\ Engineering, \\ Sudan University of Science \& Technology, \\ Khartoum, SUDAN
}

\begin{abstract}
A Geographical Information System (GIS) utility, such as network analysis is a tool used to solve common network problem, This study is intended to use GIS as a tool of analyzing. integrating and displaying information. the overall activities of the work were concentrated around sub area selected as the study site in the Khartoum north city (Khartoum ) of main capital, Sudan .To demonstrate the use of road network analysis, this project focused on determining the best route between too destinations, the closest facility from a given incident, and a service area for a given facility .
\end{abstract}

The present study attempt to analyze the potential use of network analysis in defining the optimal service area of different services such as hospitals, schools and university of Khartoum north.

Generally for the purposes of this project ,distance is taken as impedance in order to find the best route and the closest facility and that of travel time is taken as impedance in order to find the service area.

Keywords:- GIS, network analysis, geodatabase, shortest route.

\section{INTRODUCTION}

The management of road network is one of the most important areas of economic growth because of the link of main areas of economic development in this field. As the management of these networks requires the availability of a lot of information that must be organized according to the requirement of the work until the management achieves the required image, it is necessary to deal with these data through geographic information system, which is the performance that contains all the information and can be managed in the required way, which enables analyzing network in terms of density and traffic and other information that achieve the main objective of the analysis of the road network.

This research deals with the importance of geographic information systems in the analysis of road network and linking them to other service information to improve the performance of the processes of defrosting and speeding up service .

The aim of this research is to prepare its system to identify the appropriate paths on the road network.

\author{
Hajir Khaild Elshaikh Idris \\ Department of Surveying Engineering, College of \\ Engineering, \\ Sudan University of Science \& Technology, \\ Khartoum, SUDAN
}

Khartoum is a center for economic and population growth .this research concern of ( Khartoum north) to conduct this study by analyzing the road network and selecting suitable routes for service centers ( school universities , hospital and industrial area ).

\section{OBJECTIVES OF THE STUDY}

The main objectives of this study is to:

$>$ Finding the best route for services area.

$>$ Finding the optimum route to the hospitals from accidence location.

$>$ Finding the optimum arriving time to establishment such as ( school, universitis)

\section{DATA AND METHODS}

\section{A. Data and Sources}

In order to apply the network analysis to Khartoum north and determine the location of the closet facilities, the best route to it and determine the services area's coverage of any group of facilities, Khartoum map were used to create a shape files of information, Shape files were created for parcel ,road, industrial area , hospital ,school and universities, using information from different sources .Data types and sources shown in table (1)

\begin{tabular}{|c|c|c|c|}
\hline No. & Data Name & $\begin{array}{c}\text { Type of } \\
\text { Layer }\end{array}$ & Source of data \\
\hline 1. & Parcel & Polygon & $\begin{array}{c}\text { Ministry of construction } \\
\text { planning }\end{array}$ \\
\hline 2. & Road & Line & $\begin{array}{c}\text { Tracing from Google } \\
\text { Earth }\end{array}$ \\
\hline 3. & $\begin{array}{c}\text { Industrial } \\
\text { area }\end{array}$ & Polygon & $\begin{array}{c}\text { Ministry of Industry and } \\
\text { Investment }\end{array}$ \\
\hline 4. & Hospital & Polygon & $\begin{array}{c}\text { Tracing from open street } \\
\text { map+ }\end{array}$ \\
\hline 5. & School & Polygon & $\begin{array}{c}\text { Tracing from open street } \\
\text { map+ }\end{array}$ \\
\hline 6. & Universities & Polygon & $\begin{array}{c}\text { Tracing from open street } \\
\text { map }\end{array}$ \\
\hline
\end{tabular}

Table 1:- Types and Resource of Data

\section{B. Study Area}

The Study area of this study is located in the Khartoum north, Khartoum north is a piece of Khartoum town which is capital of Sudan ,geographically the study area is bounded between $15^{\circ} 37^{\prime} 00^{\prime \prime} \mathrm{N}$ latitude, $32^{\circ} 27^{\prime}$ $00^{\prime \prime} \mathrm{E}$ longitude and $15^{\circ} 25^{\prime} 30^{\prime \prime} \mathrm{N}$ latitude, $32^{\circ} 42^{\prime} 00^{\prime \prime}$ 
E longitude, which has representing the modern urban planning, this area is crowded since it's incorporate all emergency clinics, colleges ,schools ,services and business focuses, which make it as the focal point of transportation. Figure (1) represents the study area .

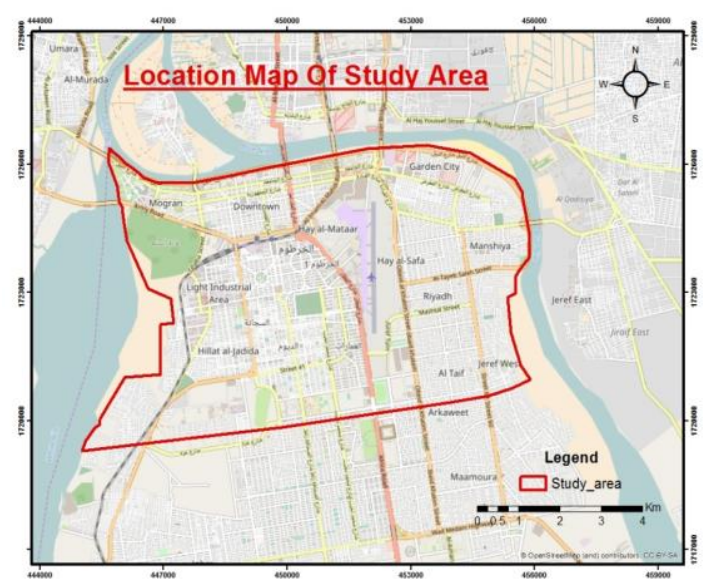

Fig 1:- The Study Area ( Khartoum North )

\section{Soft Ware Used}

The software used for this study are as follows:

$>$ ARCGIS software was use for geo-referencing Map , built topology and analyzing network .

$>$ Google Map was used to getting the locations of facilities (universities).

\section{Methodology}

The procedures used for the study are outlined as represented in figure (2).

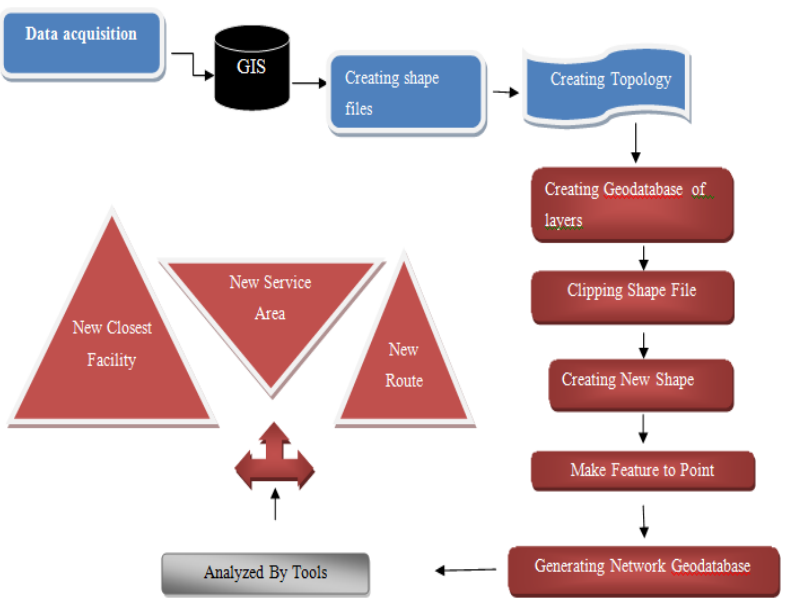

Fig 2:- The Flow Chart of the Study

\section{E. Topolooy}

To devoid and remove all roads that aren't within the area of this study,trim the mis-extention of the road that had resulted from tracing and to being in sure all coursed road are meeting in point, topology was created and figure (3) represents the topological network of the study area.

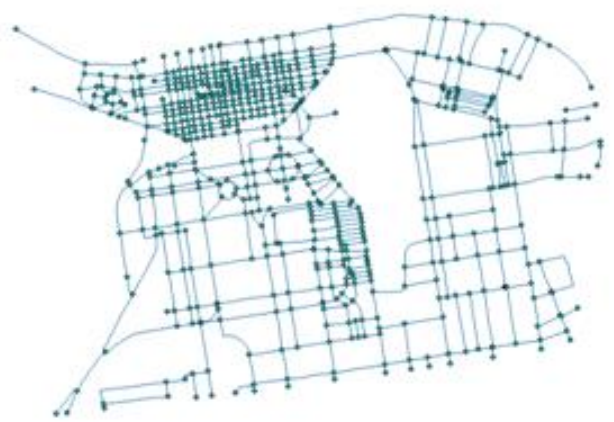

Fig 3:- The Topology Network

\section{F. Creating Geodata Base Feature Class}

The shape file were converted to geodatabase as follows:

$>$ Khartoum north road network Geo-database.

$>$ Geo-database of public services such as school, universities and hospital

$>$ Generating Network Geo-dataset :

The ArcGIS Network Analyst expansion permits you to assemble a system dataset and perform examinations on a system dataset.

In this investigation it was required information as a component classes, the accompanying advance was finished.

An advancement bar opens giving you that Network Analyst is making the system dataset.

When the system is made, the framework inquires as to whether you need to fabricate it. The construct procedure figures out which organize components are associated and populates the qualities of the system dataset. You should manufacture the system before you can play out any system investigation on it, Click Yes, The Build Network Dataset progress bar opens; it will vanish when the construct procedure is done.

The street organize and spatial circulation of various administrations (schools, universities, hospitals) were represented in figure (4)

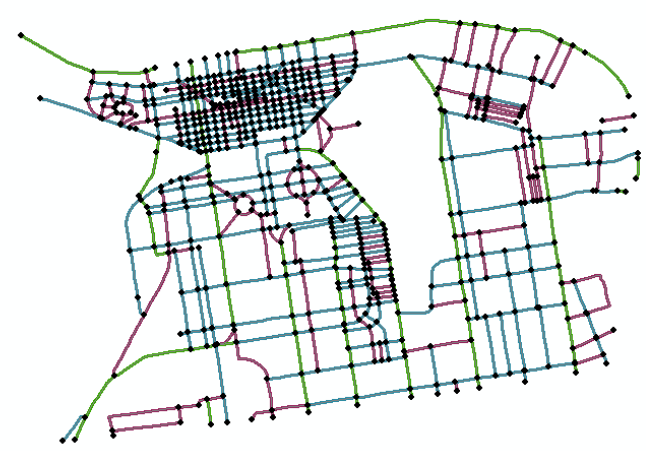

Fig 4:- The Road Network 


\section{RESULS AND ANALYSIS}

\section{A. Results of The Study}

The genuine assistance territory of the examination zone of various office or whether these offices are sufficient for that zone, on the off chance that not, at that point what amount is required, this inquiries were ansowred utilizing GIS organize investigation device. For the current examination, administrations, for example, clinics, schools, college ) were picked for investigation reason and characterize their administration region dependent on schedule and separation.

The guide spoke to in figure (5) shows the Map of Different Services, for example, clinics, schools, college through a system. This is additionally called as administration portion investigation. Since the portions of these administrations characterize the degree of their administration zone and the fundamental goal of spatial distribution investigation is to quantify the effectiveness of these administrations as far as time and separation.

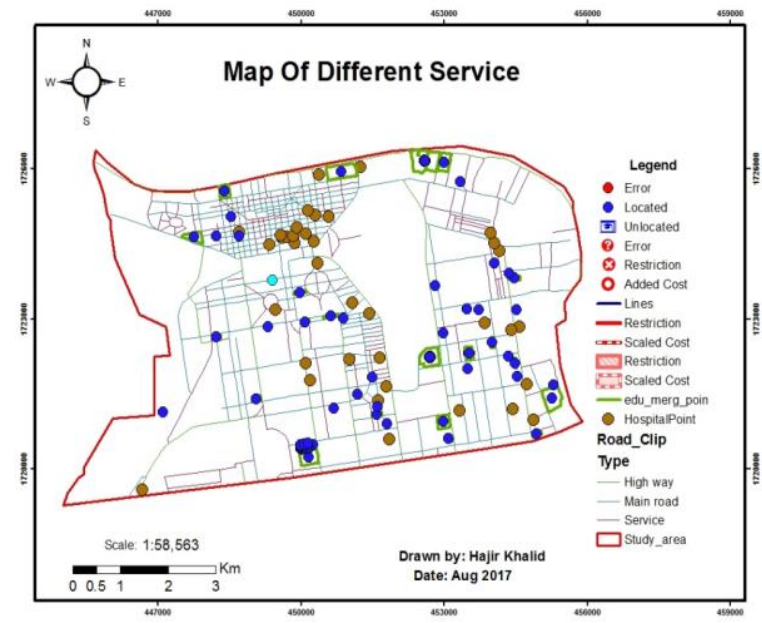

Fig 5:- Map of Different Services

Figure (6) shows Map of Service Area of various nearest offices dependent on the separation and time.

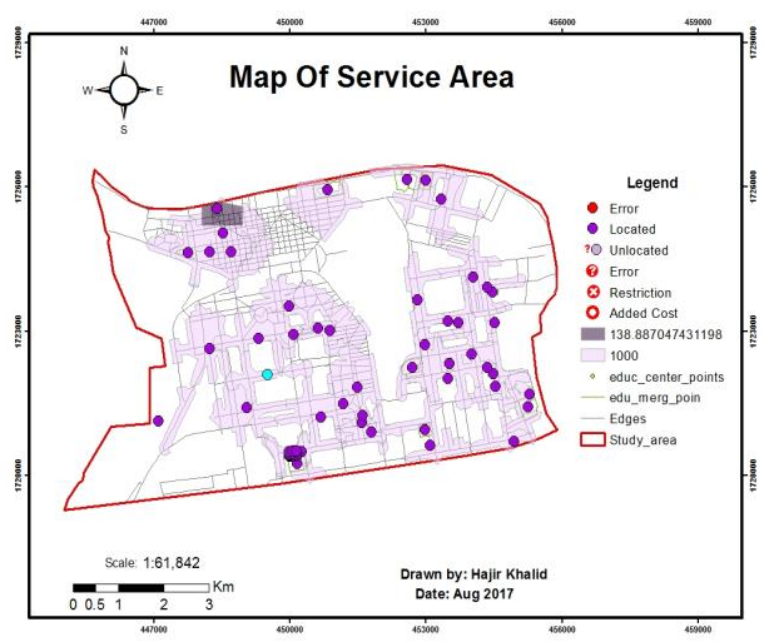

Fig 6:- Map of Service Area based on distances and time
The Services Area of Education zone which demonstrates the genuine help territory with effectiveness ,The administration region of Education Area with a different supports of 2, 4, 6 minutes(Time) indicating the real assistance zone with proficiency, Figure (7) speaks to the Map of Education Area (Time)

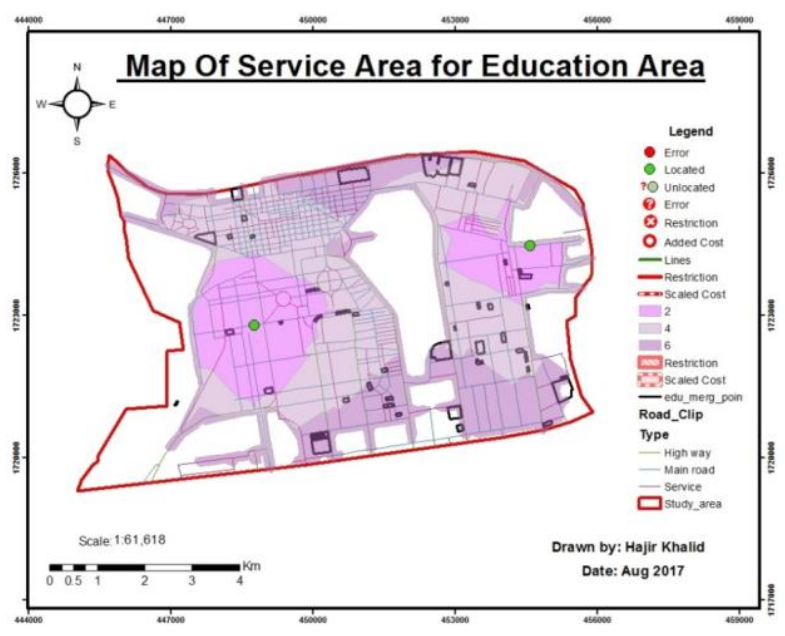

Fig 7:- Map of Service Area for Education Area(time)

Figure(8) shows the Service Area of Education territory dependent on various cradles of 1000/2000/3000 meters(Distance) with high, moderate and low effective help region of the Education zone individually.

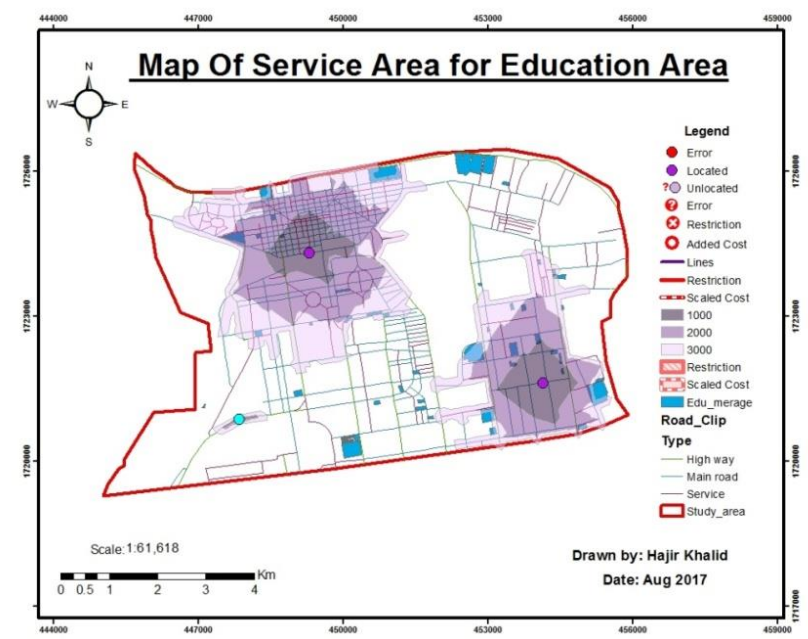

Fig 8:- Map of Service Area for Education Area(distance)

The Service Area of every medical clinic dependent on the various cradles of assessed travel time of 2, 4, and 6 minutes(Time) which shows the genuine help zone with productivity, figure (9) speak to the Map of Service Area for Hospital(Time). 


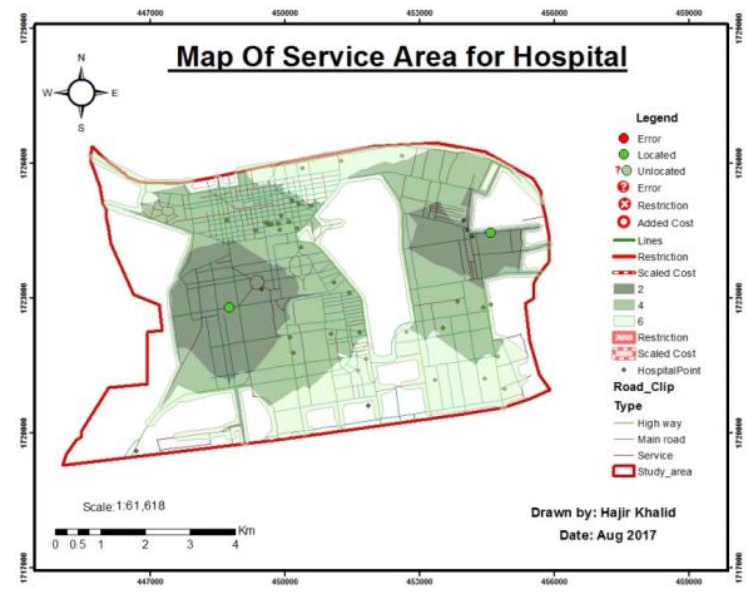

Fig 9:- Map of Service Area for Hospital(time)

This Service Area map of Hospitals with multiple buffers is based on distance interval of 1000 meters, 2000 meters and 3000 meters(Distance) showing the actual service area with efficiency,Figure (10) shows map of Service Area for Hospital (Distance)

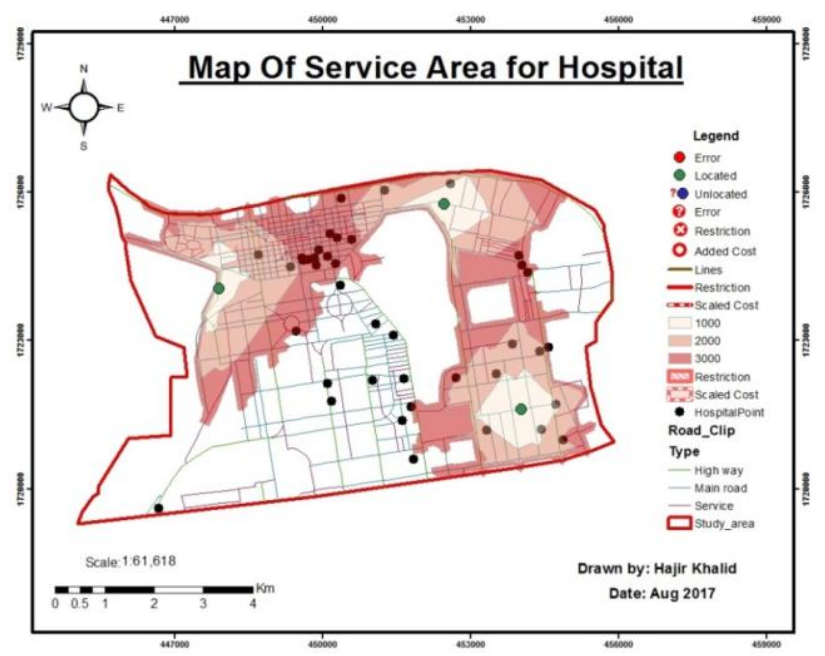

Fig 10:- Map of Service Area for Hospital(distance)

\section{$>$ Identify the shortest route between two locations}

By utilizing Network Analysis Tools "New Route" was made between two unique areas, which is increasingly productive as far as less time and hence, cost expended in voyaging. Most brief course investigation finds the course with least aggregate impedance between Nodes on a Network. The course may interface only two Nodes - a cause and a goal or have explicit stop between these two hubs, figure (11) and (12) represents map of new route between two locations and map of optimum route of hospital respectively.

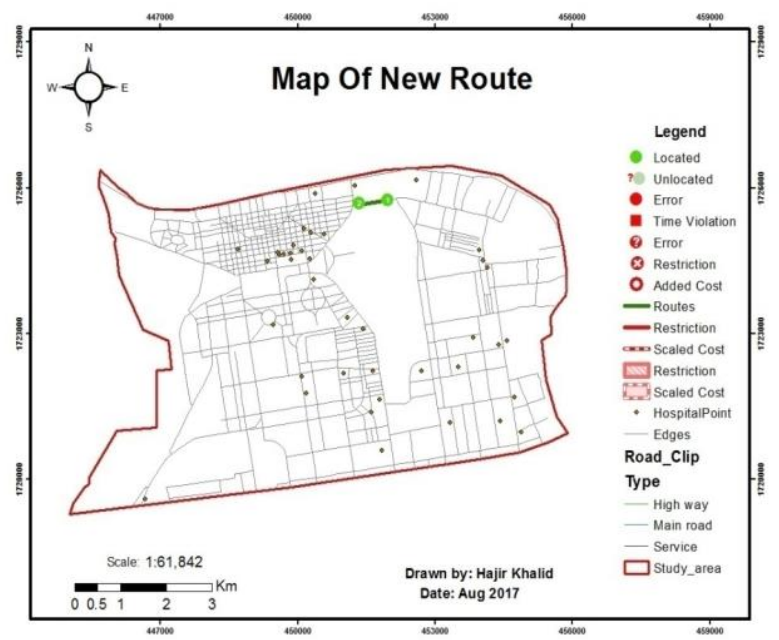

Fig 11:- Map of New Route

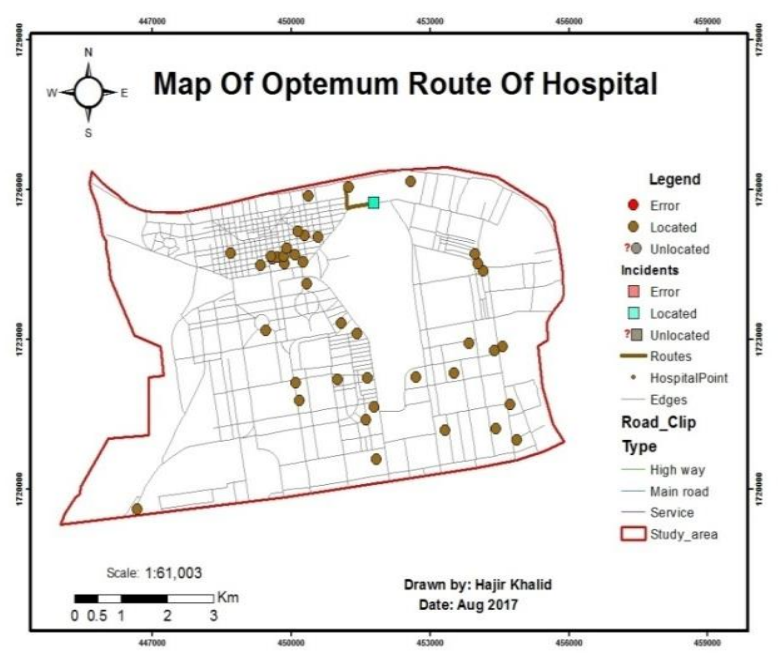

Fig 12:- Map of Optimum Route of Hospital

\section{B. Analysis of Results}

The ArcGIS Network Analyst Extension permits you to take care of normal Network issues, for example, finding the Best Route over a city, finding the Closest Emergency Vehicle or Facility, recognizing a Service Area around an area, overhauling a lot of requests with an armada of vehicles, or picking the Best Facilities to Open or Close .In this study, optimum route, service area and closest facilities has been done for analysis.

\section{$>$ Optimum Route (Distance and Time)}

Utilizing the Network Analyst "New Route" device to finding the best, briefest course and increasingly productive in less time and diminishing the expense expended between two areas ,the second favorable circumstances of this instrument is can consider a few limitations in course which tackle this issue by finding the subsequent need course to surpass this boundary, Also gives report to portray patterns and ways that must be followed. Figure (13) represents the new route. 


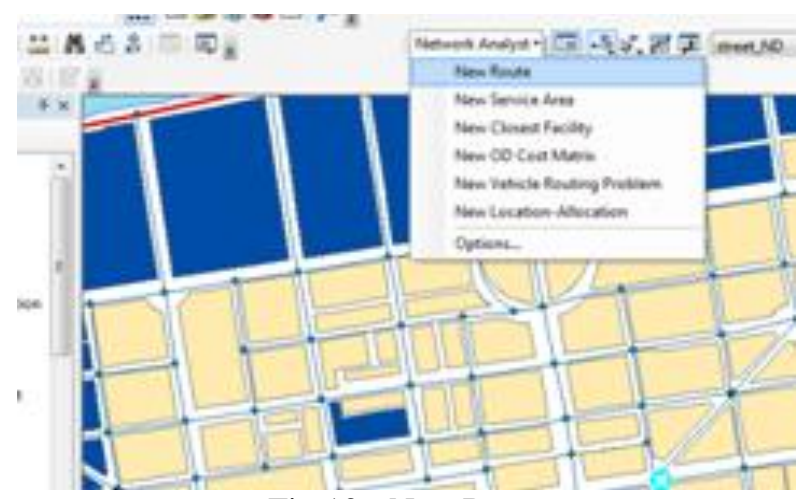

Fig 13:- New Route

Figures (14)(15) and (16) represents layer properties of new route, load location of new route and direction.

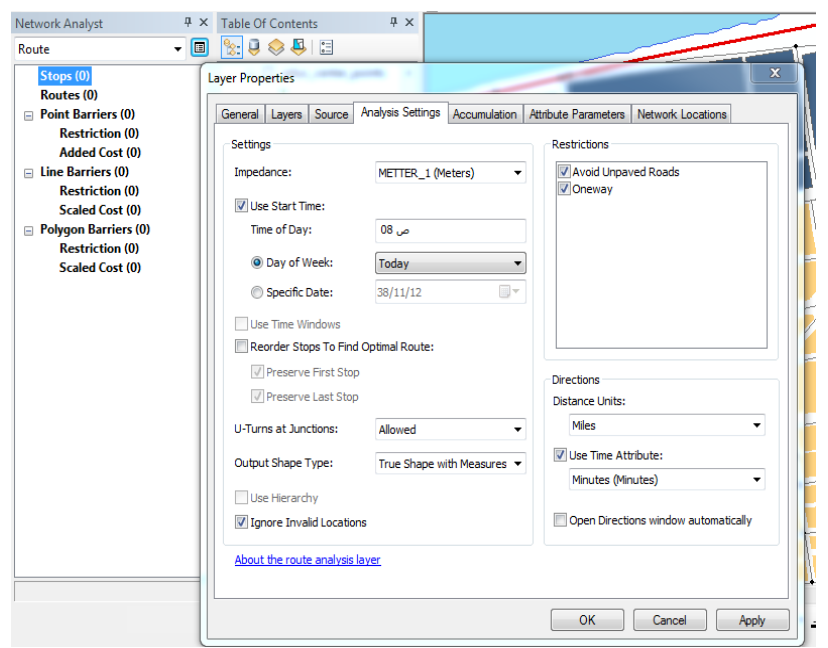

Fig 14:- Layer Properties of New Route

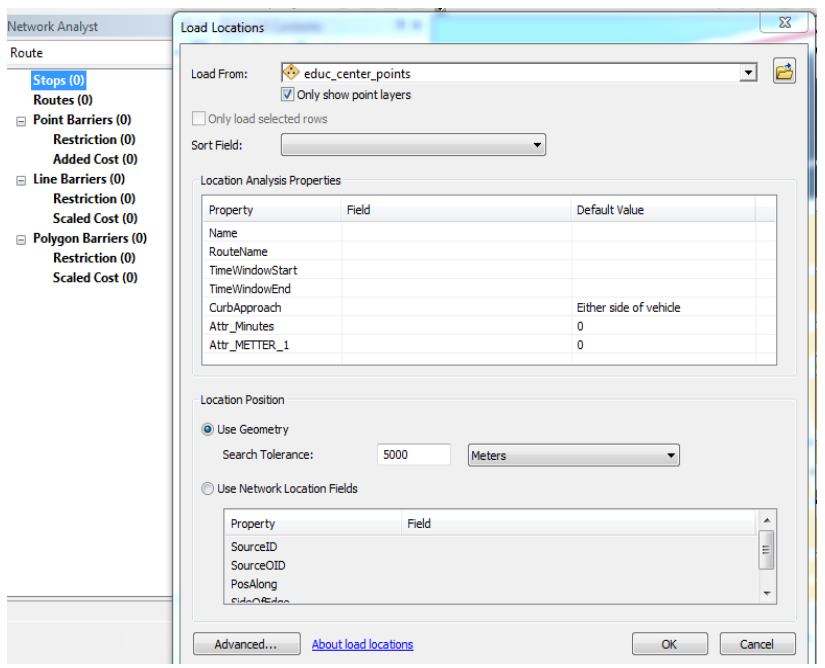

Fig 15:- Load Location of New Route

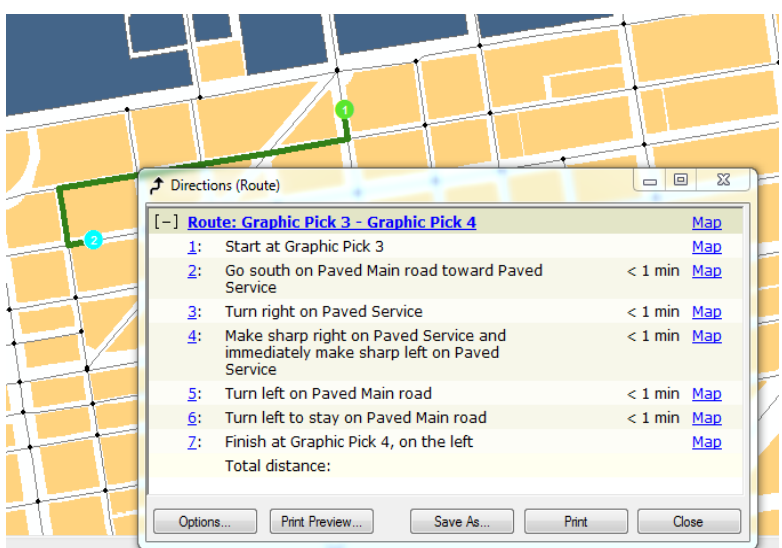

Fig 16:- Direction of New Route

\section{Service Area}

Fixing the region acted by specific Facilities rely upon time to arrive at these offices and the region need to assemble new Facility. To ascertain Network Analysis (Service Area ) of explicit class of Facilities (school, college, emergency clinic and modern zone) to gauge the productivity of these Services as far as Time and Distance, and to decide whether these Facilities are useful for that region or not, in the event that not, at that point what amount is required and best area of it four assistance region polygons determined for every Facility, dependent on drive time. Figure (17) represents the service area

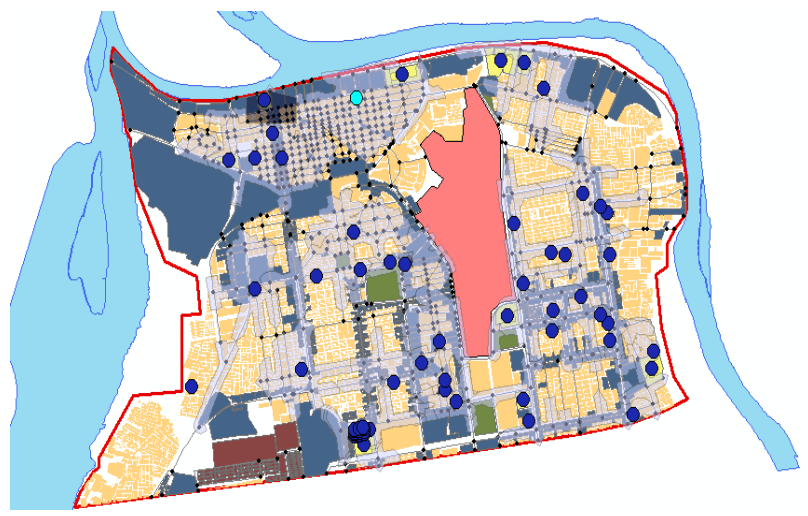

Fig 17:- The Service Area

\section{New Class Facility}

The Closest Facilities across organize rely upon time and separation to arrive at it to discover the office which has less appearance time and cost devouring or by characterize the time and separation to show up to this office utilizing the ( new storage room office ) apparatus in arrange examination, new storeroom office instrument is profitable device which backing to settle on a decent choice . Figure (18) shows the New Closets Facility of the Study Area. 


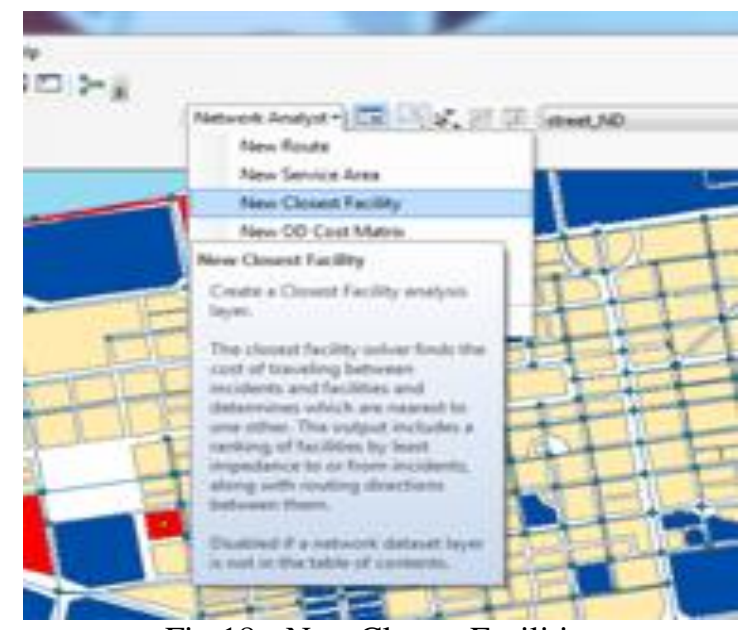

Fig 18:- New Closets Facilities

Figures (9) and (20) represents the load location of the new closets facilities and layer properties respectively.

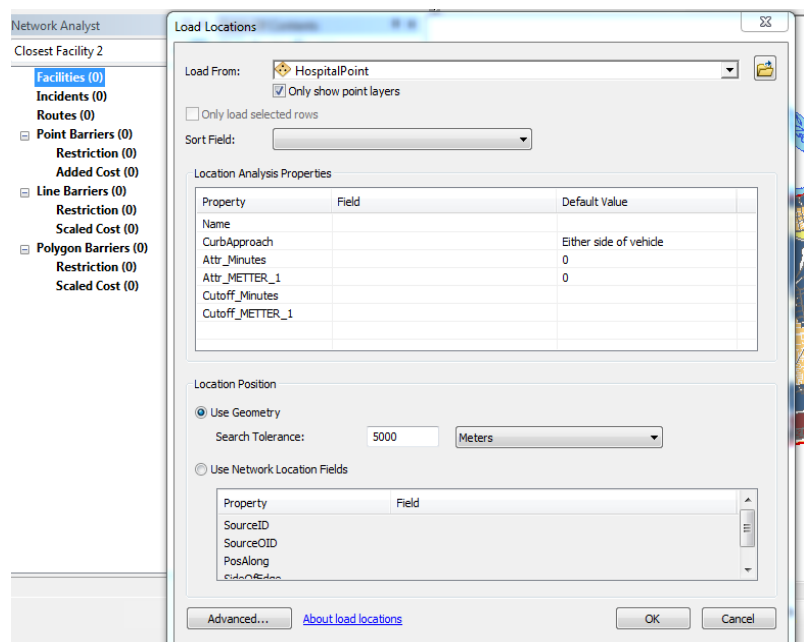

Fig 19:- Load Location of New Closet Facilities

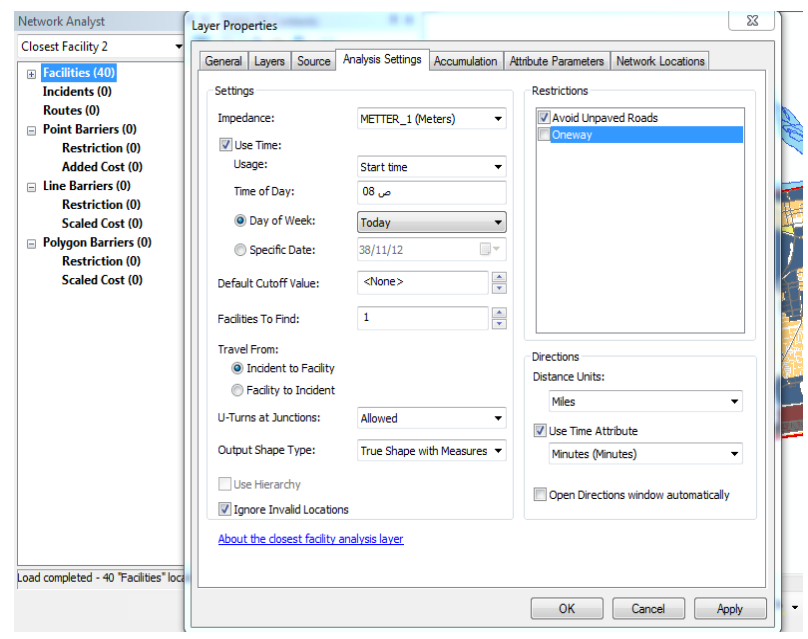

Fig 20:- Layer Properties

Figures (21) and (22) represent the solve and the direction of the new closets facilities respectively.
ISSN No:-2456-2165

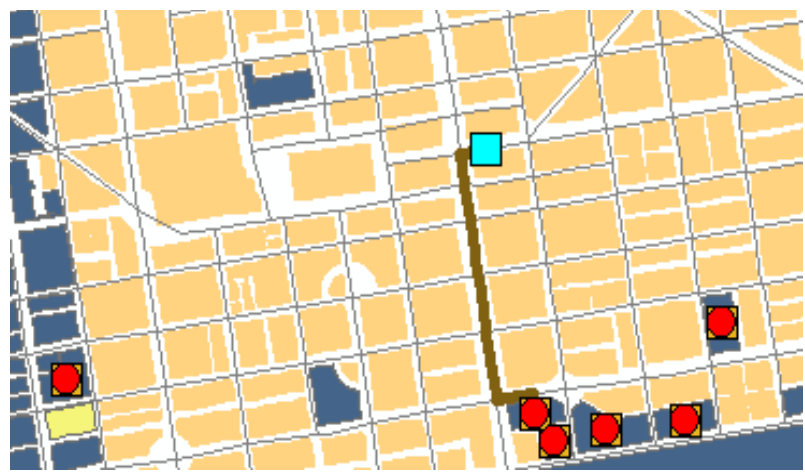

Fig 21:- Solve of the new closets facilities

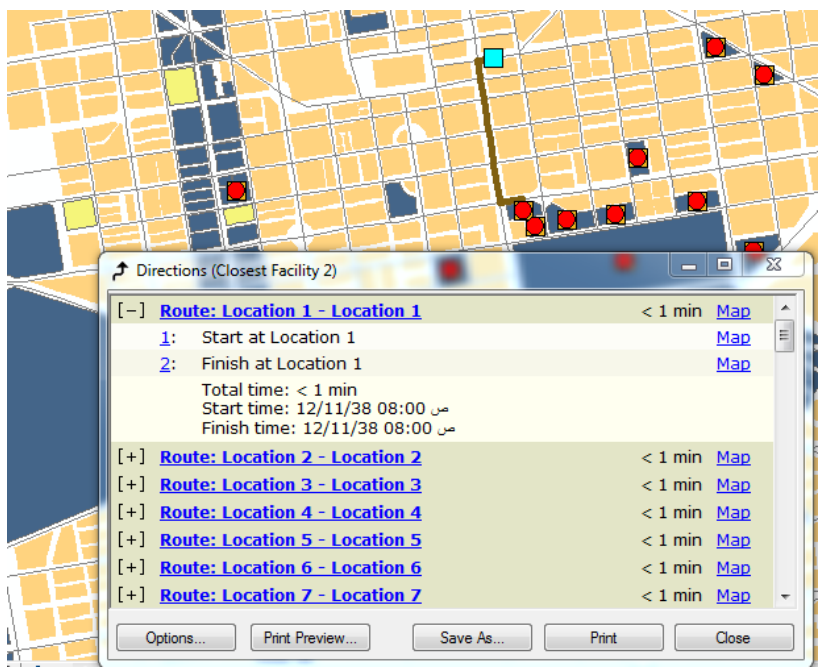

Fig 22:- Direction of the new closets facilities

\section{CONCOLUSION OF THE STUDY}

Analysis of road networks improves people activates in addition to improvement of goods and services movement. were used to analyze road network in Khartoum north. In this Study Geographic Information System and Network Analysis Tool were utilized the, it solid to quantify the productivity of Services regarding Time and Distance, to discover ideal best Route and Service Area, for example, ( college, school, clinic and business zone ), were characterized dependent on the Distance and Time and in gave of accessibility in explicit territory without the other. It is additionally help in examining the hole exist in the portion of these administrations in city region and furthermore help us in breaking down whether the current asset allotment is fortunate or unfortunate in term of productivity of these Service Area. So this investigation means to dissect the likely utilization of GIS devices for Network Analysis. Truth be told by utilizing Network Analysis Tools number of things can break down which are increasingly applicable for various sort of system investigation particularly for transport arranging we can make this kind of examination for various purposes like Shortest Path Analysis, Closest Facility Analysis, Service Area Determined Analysis and furthermore for the Best Recourses portion and for the age of Emergency Route Services, so this sort of Analysis is pivotal particularly for the vehicle based arranging. 


\section{REFERENCES}

[1]. Ahmed Dr wasan Sh , Ahmed Dr Rajaa Khaleel (2012) ,Analysis tracks cars for the city of baquba ,using technique geographic information systm (GIS), Iraq.

[2]. Elsheikh, Ranya Fadlalla Abdalla , Elhag, Abdelrahim (2015) Route Network Analysis in Khartoum City, Sudan.

[3]. Kumar Parveen , Kumar Dinesh , (2013), Network Analysis using GIS Techniques: A Case of Chandigarh city ( India).

[4]. Fischer Manfred M (2003), GIS AND NETWORK ANALYSI , Department of Economic Geography \& Geoinformatics .

[5]. https://www.geomapp.net/docs/GIS\%Definition_SA A.. 